\title{
Vertebral Artery Dissecting Aneurysm With Cushing's Syndrome -Case Report-
}

\author{
Masayasu KATO, Yoshitaka TANAKA, Tatsuya KURODA, \\ Toshihiko NAKASHIMA, and Tatsuaki HATTORI
}

Department of Neurosurgery, Gifu Prefectural General Medical Center, Gifu

\begin{abstract}
A 45-year-old woman presented with subarachnoid hemorrhage of World Federation of Neurosurgical Societies grade IV. Cerebral angiography showed a dissecting aneurysm of the right vertebral artery (VA). Internal trapping of the right VA with coils was performed. The postoperative course was uneventful, but she continued to demonstrate moon facies and experience amenorrhea. Computed tomography demonstrated an adrenal tumor. Laparoscopic adrenalectomy was performed under a diagnosis of Cushing's syndrome caused by an adrenal tumor. Overproduction of cortisol caused by Cushing's syndrome may be related to the development of cerebral aneurysm.
\end{abstract}

Key words: collagen fiber, cortisol, Cushing's syndrome, dissecting aneurysm, vertebral artery

\section{Introduction}

Dissecting aneurysms occur in many major arteries including the aorta, cerebral arteries, coronary arteries, renal arteries, etc. ${ }^{3,4,10,17,18)}$ The cerebral arteries are the second most frequent site of dissecting aneurysms after the aorta. The etiology of spontaneous cerebral dissecting aneurysm is largely unknown. Disorders leading to weakness of the vessel wall, such as Ehlers-Danlos syndrome, Marfan syndrome, fibromuscular dysplasia, and osteogenesis imperfecta, are all causes of cerebral dissecting aneurysms. ${ }^{10,14)}$ In addition, hypertension, tobacco use, migraine, infections, and oral contraceptives have been reported as risk factors. Here, we report a rare case of vertebral artery (VA) dissecting aneurysm associated with Cushing's syndrome.

\section{Case Report}

A 45-year-old woman presented with subarachnoid hemorrhage of World Federation of Neurosurgical Societies grade IV. She had a 2-year history of hypertension and recently had been noted to have moon facies. Cerebral angiography showed a dissecting aneurysm of the right VA (Fig. 1A). The aneurysmal dilatation was located just distal to the origin of the posterior inferior cerebellar artery (PICA). Balloon test occlusion of the right VA was performed. Left vertebral angiography showed retrograde filling of the distal portion of the right VA and PICA (Fig. 1B). Given the nature of the proximal occlusion, sig- nificant effects caused by preventing re-bleeding were not anticipated, so internal trapping of the right VA with coils was performed (Fig. 1C). The postoperative course was uneventful and she was discharged free of neurological deficits.

Following the surgery, the patient's moon facies and amenorrhea continued. Her 24-hour urine-free cortisol levels were elevated (187 $\mu \mathrm{g} / \mathrm{day})$. No circadian change of the plasma cortisol concentration was detected, and plasma cortisol concentration was not suppressed by high dose dexamethasone. Basal plasma adrenocorticotropic hormone levels were suppressed to undetectable levels. Computed tomography of the abdomen showed an enhanced left adrenal mass about $2.5 \mathrm{~cm}$ in diameter (Fig. 2). The diagnosis was Cushing's syndrome caused by adrenal tumor. Laparoscopic adrenalectomy was performed. The postoperative course was uneventful and her hypertension, moon face, and amenorrhea improved. Histological examination of the adrenal tumor showed cortical adenoma without atypia.

\section{Discussion}

Cushing's syndrome is characterized by overproduction of cortisol. Patients with Cushing's syndrome may develop multiple metabolic problems including obesity, hyperglycemia, hypertension, depression, low bone mass, muscle atrophy, and hypogonadism. ${ }^{12)}$ The mortality rate from cardiovascular accidents in patients with Cushing's syndrome is 4-fold higher than that of the normal population. ${ }^{2}$

Received May 28, 2009; Accepted September 8, 2009

Author's present address: M. Kato, M.D., Department of Neurosurgery, Takayama Red Cross Hospital, Takayama, Gifu, Japan. 

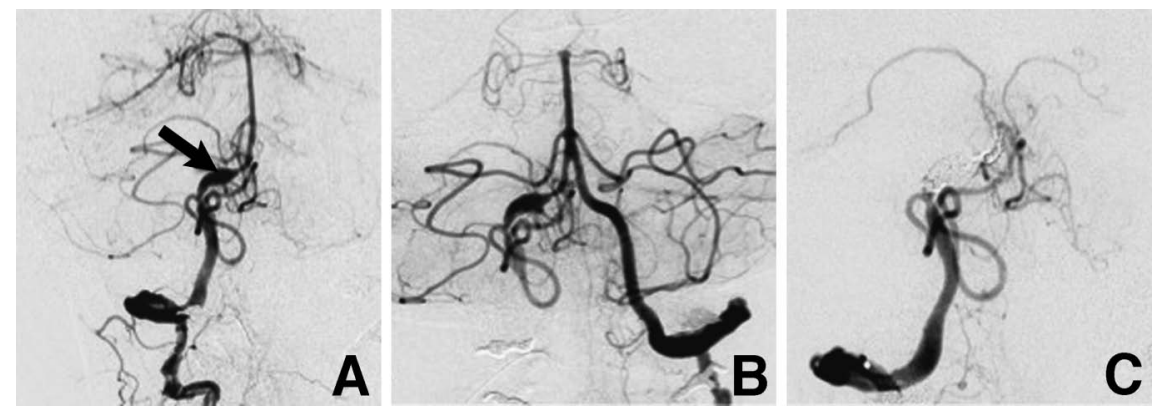

Fig. 1 A: Right vertebral angiogram showing a dissecting aneurysm of the right vertebral artery located just distal to the origin of the posterior inferior cerebellar artery (arrow). B: Left vertebral angiogram showing retrograde filling of the distal portion of the right vertebral artery and posterior inferior cerebellar artery. C: Right vertebral angiogram after internal trapping showing no filling of the dissecting aneurysm.

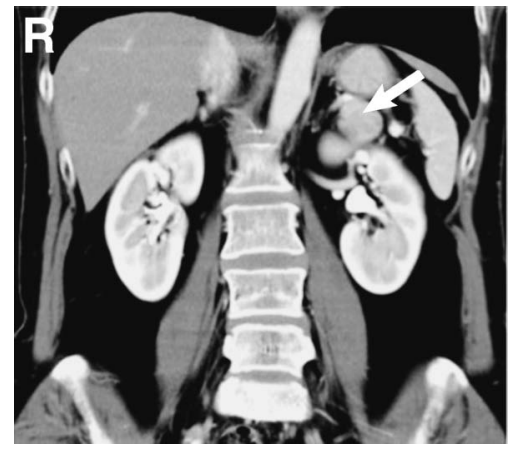

Fig. 2 Computed tomography scan of the abdomen showing an enhanced left adrenal mass (arrow).

Cushing's syndrome is a risk factor for dissecting aortic aneurysm. ${ }^{5,6,15,16)}$ Excess of plasma cortisol causes dissecting aortic aneurysm in some experimental models, ${ }^{11,13)}$ but the mechanism is unknown. Progress of arteriosclerosis due to hypertension, hyperlipemia, and diabetes originating in Cushing's disease may be the direct cause of the aortic dissection. ${ }^{6)}$ Weakness of the vessel wall due to inhibition of collagen biosynthesis and increase of the catabolism of collagen by steroid is another potential cause of the aortic dissection. ${ }^{5,7)}$

The aorta is an elastic artery which contains many elastic fibers in the media, whereas the cerebral artery is a muscular artery that lacks an external elastic lamina. Elastic fibers are concentrated inside the internal elastic lamina (IEL) of the wall of the cerebral artery. The etiology of dissecting aneurysm might differ according to the vessel characteristics, but many of the components of the arterial wall, such as elastic and collagen fibers, are similar between the aorta and cerebral arteries.

There are two possible explanations for the association between cerebral dissecting aneurysm and Cushing's syndrome. Hypertension is associated with Cushing's syndrome and is a risk factor for cerebral dissecting aneurysm. Our patient had a history of hypertension, which improved after adrenalectomy. She had no other risk factor such as tobacco use, migraine, infection, or oral contraceptives. Possibly the hypertension caused by Cushing's syndrome was related to the cerebral dissecting aneurysm.

Weakness of the vessel wall occurs secondary to an excess of plasma cortisol. The predominant pathological mechanism for cerebral dissecting aneurysm is the sudden widespread disruption of the IEL. ${ }^{8)}$ IEL defects can be observed in normal vessel walls with increasing age. ${ }^{9)}$ Sudden disruptions of the IEL may occasionally occur. However, most cases of disrupted IEL may be healed by local intimal thickening, which includes predominantly collagen proliferation, and may not develop into dissecting aneurysms. ${ }^{8)}$ Prednisolone inhibits collagen biosynthesis and increases the catabolism of collagen. ${ }^{1,7)}$ In the present case, we speculate that the excess of plasma cortisol may have inhibited the intimal thickening which might repair disrupted IEL, and thus promoted the development of cerebral dissecting aneurysm.

VA dissecting aneurysm associated with Cushing's syndrome is very rare, and the underlying cause is not clear. However, overproduction of cortisol caused by Cushing's syndrome may be related to the development of cerebral aneurysm.

\section{References}

1) Cutroneo KR, Rokowski R, Counts DF: Glucocorticoids and collagen synthesis: comparison of in vivo and cell culture studies. Coll Relat Res 1: 557-568, 1981

2) Faggiano A, Pivonello R, Spiezia S, De Martino MC, Filippella M, Di Somma C, Lombardi G, Colao A: Cardiovascular risk factors and common carotid artery caliber and stiffness in patients with Cushing's disease during active disease and 1 year after disease remission. J Clin Endocrinol Metab 88: 2527-2533, 2003

3) Golledge J, Eagle KA: Acute aortic dissection. Lancet 372: 55-66, 2008

4) Kanofsky JA, Lepor H: Spontaneous renal artery dissection. Rev Urol 9: 156-160, 2007

5) Kazama Y, Kawabe T, Noguchi T, Onaya T: [A case of Cushing's syndrome associated adrenomedullary hyperplasia and dissecting aneurysm of the aorta]. Naika 58: 1263-1266, 1986 (Jpn)

6) Kazui T, Iwaki Y, Hasegawa T, Kusajima K, Wada J: [A case 
of surgically cured acute dissecting aneurysm associated with Cushing's syndrome]. Kyobu Geka 30: 835-839, 1977 (Jpn, with Eng abstract)

7) Manthorpe R, Garbarsch C, Lorenzen I: Long-term effect of glucocorticoid on connective tissue of aorta and skin. Morphological and biochemical studies of tissues from rabbits with intact and injured aortas. Acta Endocrinol (Copenh) 95: 271-281, 1980

8) Mizutani T, Kojima H, Asamoto S, Miki Y: Pathological mechanism and three-dimensional structure of cerebral dissecting aneurysms. J Neurosurg 94: 712-717, 2001

9) Sato T, Sasaki T, Suzuki K, Matsumoto M, Kodama N, Hiraiwa K: Histological study of the normal vertebral artery-etiology of dissecting aneurysms. Neurol Med Chir (Tokyo) 44: 629-635, 2004

10) Schievink WI: Spontaneous dissection of the carotid and vertebral arteries. N Engl J Med 344: 898-906, 2001

11) Selye H, Bois P: Effect of corticoids upon experimental lathyrism. Endocrinology 60: 507-513, 1957

12) Shibli-Rahhal A, Van Beek M, Schlechte JA: Cushing's syndrome. Clin Dermatol 24: 260-265, 2006

13) Steffee CH, Snell KC: Dissecting aortic aneurysm in hamsters treated with cortisone acetate. Proc Soc Exp Biol Med 90: 712-714, 1955
14) Suyama K, Hayashi K, Nagata I: [Cervicocephalic arterial dissection]. Brain Nerve 60: 1115-1123, 2008 (Jpn, with Eng abstract)

15) Suzuki T, Sasano H, Murakami O, Nagura H: A case of ruptured dissecting aneurysm 5 years after pituitary microsurgical treatment of Cushing's disease: autopsy findings in the hypothalamic-pituitary-adrenal axis. Endocr J 40: 613-618, 1993

16) Takagi H, Furukawa M, Umeda $Y$, Fukumoto $Y$, Yoshida N, Yamada T, Mori Y: Aortic arch aneurysm with dissection in Cushing syndrome. Thorac Cardiovasc Surg 127: 278-279, 2004

17) Tsurugaya $\mathrm{H}$, Tada H: [Spontaneous coronary artery dissection]. Nippon Rinsho Suppl 5 Pt 2: 109-113, 2007 (Jpn)

18) Zhang WW, Killeen JD, Chiriano J, Bianchi C, Teruya TH, Abou-Zamzam AM: Management of symptomatic spontaneous isolated visceral artery dissection: is emergent intervention mandatory? Ann Vasc Surg 23: 90-94, 2008

Address reprint requests to: Masayasu Kato, M.D., Department of Neurosurgery, Takayama Red Cross Hospital, 3-11 Tenman-cho, Takayama, Gifu 506-8550, Japan.

e-mail: masayasu.kato@nifty.ne.jp 